\section{Meaning of the study}

We believe that publishing surgeon specific, crude mortality data, ${ }^{2}$ as is planned in the United Kingdom, is not in the best interests of patients, and our study shows that surgeons cannot be compared fairly in this way. Cardiac surgeons already work in a stressful environment, and the perception that a "bad run" might jeopardise their career or result in suspension and investigation may lead to a tendency to turn down high risk cases. The easiest way to obtain low mortality is to do only straightforward operations-so called risk averse behaviour. This has already been identified as a potential problem after a survey of all cardiac surgeons in the United Kingdom in 2000, where 94\% of responders agreed that high risk patients were being turned down for surgery. ${ }^{1}$ Death rates in these patients often approach $100 \%$ if the patients are denied surgery and patients at heightened risk from surgery are, in general, those who have the most to gain from a successful operation. ${ }^{21}$ Our recommendation of benchmarking only low risk patients seems scientifically justified and pragmatic and should help to prevent risk averse behaviour.

\section{Unanswered questions and future research}

Some evidence from North America sheds light on the effects of publication of surgeon specific data on patients, cardiologists, and surgeons, ${ }^{122}{ }^{23}$ but we do not know to what extent initiatives to publish crude mortality data for individual surgeons will actually deny operations to high risk patients, and what implications this will have on patients' survival, quality of life, and use of healthcare resources. This is an important area for future studies. Further investigations are also needed on high risk patients, to improve the quality of risk prediction in this group, and to understand variability in outcomes following high risk surgery for quality improvement purposes.

This study has been conducted on behalf of the North West Quality Improvement Programme in Cardiac Interventions, and the participating consultant surgeons are listed as follows: John Au, Ben Bridgewater, Colin Campbell, John Carey, John Chalmers, Walid Dhimis, Abdul Deiraniva, Andrew Duncan, Brian Fabri, Elaine Griffiths, Geir Grotte, Ragheb Hasan, Tim Hooper, Mark Jones, Daniel Keenan, Neeraj Mediratta, Russell Millner, Nick Odom, Brian Prendergast, Mark Pullan, Abbas Rashid, Pau Waterworth, Nizar Yonan. We would like to acknowledge the assistance of the audit officers working in each centre for their hard work in collecting and validating the data.

Contributors: BB had the idea for the study and with ADG and MJ was responsible for the study design. Data analysis was performed by ADG and MJ. The manuscript was prepared by BB and ADG. All authors contributed to writing the paper, which was written on behalf of the North West Quality Improvement Programme in Cardiac Interventions. BB will act as guarantor. Funding: All primary care trusts in the north west of England. Competing interests: None declared.

Ethical approval: The project was conducted on routinely collected prospective data. All patient identifiers were anonymised. The study therefore did not need ethical approval.

1 Keogh B, Kinsman R. National adult cardiac surgical database report 20002001. London: Society of Cardiothoracic Surgeon of Great Britain and Ireland, 2002.

2 Dyer $\mathrm{O}$, Heart surgeons are to be rated according to bypass surgery success. BMJ 2003;326:1053

3 Parsonnet V, Dean D, Bernstein AD. A method of uniform stratification of risk for evaluating the results of surgery in acquired heart disease. Circulation 1979;I3-I12
4 Tu JV, Jaglal SB, Naylor D. Multicenter validation of a risk index for mortality, intensive care unit stay, and overall hospital length of stay after cardiac surgery. Circulation 1995;91:677-84.

5 Roques F, Nashef SA, Michel P, Guaducheau E, de Vincentiis C, Baudet E, et al. Risk factors and outcome in European cardiac surgery; analysis of the EuroSCORE multinational database of 19,030 patients. Eur J Cardiothorac Surg 1999;15:816-23.

6 Nashef SA, Carey F, Silcock MM, Oomen PK, Levy RD, Jones MT. Risk stratification for open heart surgery: trial of the Parsonnet system in a British hospital. BMJ 1992;305:1066-1067.

7 Bridgewater B, Neve H, Moat N, Hooper T, Jones M. Predicting operative risk for coronary artery surgery in the United Kingdom: a comparison of various risk prediction algorithms. Heart 1998;79:350-5.

8 Wynn-Jones K, Jackson M, Grotte G, Bridgewater B, and the Northwest Region Cardiac Surgery Audit steering group. Limitations in the Parsonnet score for measuring risk stratified mortality in the north west of England. Heart 2000; 84:71-8.

9 The Northwest regional quality improvement program in adult cardiac surgery. www.nwheartaudit.nhs.uk (accessed 10 Jun 2003).

10 Nashef SAM, Roques F, Michel P, Gauducheau E, Lemeshow S, Salamon R, the EuroSCORE study group. European system for cardiac operative risk evaluation (EuroSCORE). Eur J Cardiothorac Surg 1999;16:9-13.

11 Roques F, Nashef SAM, Michel P, Pinna Pintor P, David M, Baudet E. Does the EuroSCORE work in individual European countries? Eur J Cardiothorac Surg 2000;18:27-30.

12 Nashef SAM, Roques F, Hammill BD, Peterson ED, Michel P, Grover FL, et al. Validation of the European system for cardiac operative risk evaluation (EuroSCORE) in North American cardiac surgery. Eur J Cardiothorac Surg 2002;22:101-5.

13 Hanley JA, McNeil BJ. The meaning and use of the area under a receiver operating characteristic (ROC) curve. Radiology 1982;143:29-36.

14 Swets JA. Measuring the accuracy of diagnostic systems. Science 1988:240:1285-93.

15 Fine LG, Keogh BE, Cretin S, Orlando M, Gould MM. How to evaluate and improve the quality and credibility of an outcomes database: validation and feedback study on the UK Cardiac Surgery Experience. BMJ 2003;326:25-8.

16 Coronary artery bypass surgery in New York State 1997-1999. Albany, NY: New York State Department of Health. 2002. www.health.state.ny.us (accessed 10 Jun 2003).

17 Roques F, Michel P, Goldstone AR, Nashef SAM. The logistic EuroSCORE. Eur Heart J 2003;24:1-2.

18 Speigelhalter DJ. Mortality and volume of cases in paediatric cardiac surgery: retrospective study based on routinely collected data. BMJ 2002;324:261

19 Hannan EL. The relation between volume and outcome in health care. N Engl J Med 1999;340:1677-1679.

20 Hannan EL, Kilburn H, Bernard H, O'Donnell JF, Lukacik G, Sheilds EP. Coronary artery bypass surgery; the relationship between inhospital mortality rate and surgical volume after controlling for clinical risk factors. Med Care 1991;29:1094.

21 Westaby S. League tables, risk assessment and an opportunity to improve standards. BrJ Cardiol (Acute interv Cardiol) 2002;9:AIC5-AIC10.

22 Schneider EC, Epstein AM. Use of public performance reports; a survey of patients undergoing cardiac surgery. JAMA 1998;279:1638-42.

23 Hannan EL, Stone CC, Biddle TL, DeBuono BA. Public release of cardiac surgery health outcomes data in New York: what do New York State cardiologists think of it. Am Heart J 1997;134:55-61.

(Accepted 17 June 2003)

\section{Corrections and clarifications}

ABC of diabetes: cardiovascular disease, hypertension, and lipids

Owing to an electronic problem, we had to retype many of the symbols in this article by Peter J Watkins, and inevitably we slipped up on one (19 April, pp 874-6). The fourth paragraph in the section on blood pressure management should read: "Blood pressure $>140 / 80 \mathrm{~mm} \mathrm{Hg}$ [not $<140 / 80 \mathrm{~mm} \mathrm{Hg}]$ should be treated if there is evidence of organ damage ... The target pressure is $<$ 140/80 mm Hg."

Accuracy of Ottawa ankle rules to exclude fractures of the ankle and mid-foot: systematic review

An error crept into the diagram of the Ottawa ankle rules in this article by Lucas M Bachmann and colleagues (22 February, pp 417-9). The medial view of the ankle should have been labelled:

"Posterior edge or tip of the medial [not lateral] malleolus $-6 \mathrm{~cm}$." 